\title{
Does Neighborhood Belonging Matter? Examining School and Neighborhood Belonging as Protective Factors for Latino Adolescents
}

\author{
Laura K. Maurizi, Rosario Ceballo, Quyen Epstein-Ngo, and Kai S. Cortina \\ University of Michigan
}

\begin{abstract}
Across many investigations, school belonging has been linked to several positive outcomes among adolescents, including academic success and psychological well-being. Based on an ecological framework of child development, this study expands on existing research to explore factors that contribute to adolescents' sense of neighborhood as well as school belonging and investigates how belonging in both contexts is related to Latino adolescents' academic and psychological functioning. Participants consisted of 202 Latino adolescents residing in low-income, urban neighborhoods. Structural equation modeling demonstrated that neighborhood peer support was significantly associated with adolescents' sense of neighborhood belonging, whereas teacher support and school peer support were related to school belonging. Although school belonging was positively associated with higher scores on all academic indicators, neighborhood belonging was negatively related to academic aspirations and expectations, grades, and educational values. Yet, both school and neighborhood belonging were associated with better psychological functioning as manifested by lower reported levels of depression. The importance of investigating Latino adolescents' development within multiple contexts is discussed.
\end{abstract}

$\mathbf{A}$ $\mathrm{s}$ the fastest growing ethnic minority group, there were approximately 52 million Latinos residing in the United States in 2011, representing nearly $17 \%$ of the total U.S. population (U.S. Census Bureau, 2011). Among children living in poverty, Latino youth are disproportionately overrepresented: $34 \%$ of Latino children live below the poverty line compared with $14 \%$ of non-Latino White children (U.S. Census Bureau, 2011). Latino children are thus more likely to be exposed to a host of structural disadvantages including neighborhood crime, poor health care, and underfunded schools (Garcia-Reid, Reid, \& Peterson, 2005; National Center for Education Statistics, 2007). Moreover, the educational attainment of Latino youth is remarkably low on almost every marker of academic achievement (e.g., achievement test scores, drop-out rates, graduation rates, college attendance). Compared with $9 \%$ of non-Latino Whites over the age of 25 who do not have a high school degree, $37 \%$ of Latinos have not received

Funding for this study was provided to the second author by the National Center for Institutional Diversity (NCID) and the Office of the Vice President for Research in the College of Literature, Science and the Arts (LSA) at the University of Michigan, Ann Arbor. We are thankful to welcoming school administrators and staff as well as to the students whose willingness to share their experiences made this study possible. We are also grateful for our research team's dedication and hard work. Finally, we wish to thank Abby Stewart for her generous and insightful feedback on an earlier version of this manuscript.

Correspondence concerning this article should be addressed to Laura K. Maurizi, Department of Psychology, University of Michigan, 530 Church Street, Ann Arbor, MI 48109. Electronic mail may be sent to laurakm@umich.edu. high school diplomas (U.S. Census Bureau, 2011). This study seeks to improve our understanding of how both school and neighborhood contexts influence the academic and psychosocial adjustment of a highly disadvantaged group - Latino adolescents from low-income families.

Baumeister and Leary (1995) identify the "need to belong" as a fundamental human motivation, crucial to cognitive processes and positive affect. Belonging is thus a critical component in the investigation of social mechanisms that promote academic achievement and psychological well-being for at-risk youth. While many investigations center on the family context and document the importance of the family setting for children's development, far fewer studies consider other important settings (Bronfenbrenner, 1994). Relying on an ecological framework of development (Bronfenbrenner, 1989) and the press to attend to various contextual settings in a child's life, the present study explores Latino adolescents' sense of belonging in two different yet important contexts: schools and neighborhoods. For all adolescents, schools and neighborhoods are two primary settings that impact future developmental trajectories (Eccles, 2004). To date, research on belonging has primarily focused on the school context and has rarely examined aspects of neighborhood belonging or a broader range of outcomes beyond academic achievement (Fredricks, Blumenfeld, \& Paris, 2004). Our study simultaneously examines belonging in school and neighborhood contexts and their association with both school and mental health outcomes.

In the current study, we first examine factors that contribute to adolescents' sense of belonging to their schools and their neighborhoods. Second, we investigate the influence of school 
and neighborhood belonging on Latino adolescents' academic and psychological functioning. Rather than rely on indicators of contextual settings as objectified in census data, our study examines adolescents' own perceptions of their environments. As individuals vary in their personal assessments of similar neighborhood settings (Dahl, Ceballo, \& Huerta, 2010), it is not surprising that adolescents' subjective perceptions of schools and neighborhoods are important predictors of wellbeing and learning behaviors in school (Roosa, Jones, Tein, \& Cree, 2003). As such, simultaneous investigation of adolescents' sense of belonging in both school and neighborhood contexts is necessary in furthering our understanding of the role that belonging can play in the academic and psychosocial adjustment of at-risk youth.

\section{School Belonging}

A sense of belonging includes an individual's sense of acceptance and of being valued, included, and encouraged by others in a community (Goodenow, 1993). A combination of several factors typically contributes to students' sense of school belonging including teacher support, school-based activity involvement, and peer support, which are among the most salient factors (Brown \& Evans, 2002; Faircloth \& Hamm, 2005). Teacher support and involvement in the classroom positively impact students' sense of school belonging as well as contribute to greater academic engagement and higher self-regulated learning (Brown \& Evans, 2002; Faircloth \& Hamm, 2005; LaRusso, Romer, \& Selman, 2008). Similarly, involvement in schoolbased extracurricular activities is linked to students' feelings of school belonging (Brown \& Evans, 2002; Faircloth \& Hamm, 2005). On the whole, involvement in a variety of after-school programs is associated with positive well-being, stronger academic orientation, and decreased levels of depression (Fredricks \& Eccles, 2005, 2006; Mahoney \& Cairns, 1997; Mahoney, Lord, \& Carryl, 2005). In contrast, peer harassment and difficulty with peers are associated with lower levels of school belonging and academic achievement (Eisenberg, NeumarkSztainer, \& Perry, 2003; Water, Cross, \& Shaw, 2010) with some evidence of peer difficulty temporally preceding a lower sense of school belonging in the ninth grade. Thus, in the present study, we hypothesize that the following three factors will all contribute to Latino adolescents' sense of school belonging: (a) teacher support, (b) involvement in school-based activities, and (c) peer support at school.

\section{Neighborhood Belonging}

Despite evidence that a sense of belonging plays an important role in adolescent outcomes, a scarcity of research examines what factors contribute to adolescents' sense of belonging in neighborhood contexts and how neighborhood belonging may influence educational and psychological outcomes (Chipuer, 2001). Instead, researchers have focused on the relations between objective neighborhood characteristics, whether of affluence or poverty, and their relation to developmental outcomes (Leventhal \& Brooks-Gunn, 2004). The present study expands upon previous research by simultaneously comparing how Latino adolescents' subjective sense of belonging to both schools and neighborhoods may influence their academic success and psychological well-being. In keeping with our prior hypotheses on adolescents' school belonging, we similarly examine how neighborhood-based activities and neighborhood peer support are related to adolescents' sense of neighborhood belonging.

Many studies on extracurricular involvement fail to specify whether children's activities are school based or neighborhood based and thus are unable to evaluate whether youth who report little or no involvement in school-based activities may instead be involved in community-based activities (Shanahan \& Flaherty, 2001). Naturally, the influence of any neighborhoodbased activity involvement will depend, in part, on the quality and structure of the particular program. Hirsch, Deutsch, and DuBois (2011) identified several important aspects of participation in community-based programs that promote positive youth outcomes; these include program quality, types of activities, relationships with staff members or peers, and the program's overall culture. Likewise, Fogel (2004) posited that adolescents' perceptions of non-kin adults, such as program mentors and staff, are a significant and often overlooked social aspect of neighborhood experiences that may contribute to a sense of neighborhood belonging. Likewise, given that social relations and peer group formation are of paramount importance during adolescence, it is likely that peer-based support networks also influence adolescents' sense of belonging to contexts other than school. Unfortunately, studies of neighborhood peers are often biased toward the study of gang membership and delinquent peer groups, thereby failing to examine the effects that positive peer relationships in a neighborhood context may have on adolescent outcomes. Hence, we anticipate that both positive neighborhood peer relationships and involvement in neighborhood-based activities will be positively related to adolescents' sense of neighborhood belonging.

\section{Sense of Belonging, Academic Attitudes, and Psychological Well-being}

\section{School Context}

Numerous studies have found a positive association between school belonging and educational outcomes such as academic achievement, educational values, motivation, and school effort (Anderman, 2003; Roeser, Midgley, \& Urdan, 1996; Steinberg, Dornbusch, \& Brown, 1992). When focusing specifically on Latino youth, researchers continue to find a beneficial impact of school belonging on various academic outcomes such as achievement motivation and school effort (Ibanez, Kuperminc, Jurkovic, \& Perilla, 2004; Sanchez, Colon, \& Esparza, 2005). Among a sample of high- as well as low-achieving Mexican American students, Gonzalez and Padilla (1997) found that school belonging was the only significant predictor of grades, even when accounting for supportive academic environments. Yet, a study with predominantly White students reported that school belonging had a positive but small effect on year-end grades after controlling for prior academic achievement (Roeser et al., 1996). Overall, a number of studies indicate that school belonging promotes positive academic values and beneficial school behavior among Latino adolescents. In this study, we 
investigate the influence of school belonging on adolescents' educational attitudes and academic functioning. We specifically predict that higher levels of school belonging will be associated with greater academic aspirations and expectations, higher selfreported grades, educational values, and school effort.

Despite the known relationship between poor mental health and negative school outcomes (e.g., lower grades and motivation, higher truancy and dropout), research has only recently begun to examine the mechanisms by which school contexts may impact students' mental health (Herman, Reinke, Parkin, Traylor, \& Agarwal, 2009). There is some evidence that the benefits of school belonging extend beyond positive effects on academic values and behavior to also influence adolescents' psychological well-being. For example, in several studies, adolescents who report a greater sense of school belonging demonstrate lower levels of anxiety, depression, feelings of loneliness, and stress (Chipuer, 2001; Ozer, 2005; Shochet, Dadds, Ham, \& Montague, 2006). Ozer's (2005) study with an ethnically diverse, urban sample of 73 adolescents, $40 \%$ of whom identified as Latino, provided longitudinal evidence for the role of school belonging as a protective factor for adolescents' mental health. In the current study, we examine the relationship between school belonging and two indicators of psychological well-being: anxiety and depressive symptoms. Our focus on internalizing behavior rounds out current research on schools that usually investigates externalizing behaviors. Further, traditional views of mental health tend to focus on internal processes that influence depression rather than examining psychosocial and sociocultural factors (Herman et al., 2009). In our study, we predict that school belonging will be linked to adolescents' psychological well-being such that higher levels of school belonging will be associated with lower levels of anxiety and depression.

\section{Neighborhood Context}

Less attention has been given to the impact of neighborhood belonging on adolescents' academic outcomes and psychological functioning. Conchas (2001) argued that neighborhood social support is particularly salient for those students negatively affected by the belief that race and class limit their educational opportunities. Quane and Rankin (2006) found that involvement in neighborhood organizations (e.g., Boy or Girl Scouts, organized sports, religious youth groups, YMCA) promotes academic commitment and educational expectations, especially for adolescents living in disadvantaged neighborhoods. Thus, we hypothesize that neighborhood belonging will be associated with increased academic aspirations, academic expectations, self-reported grades, educational values, and school effort.

More recently, studies have examined how neighborhood belonging may influence psychological well-being. Several researchers have found that a sense of community and adult support are associated with fewer feelings of loneliness and worry, more happiness and life enjoyment, greater academic competence, more prolonged engagement in school, and higher school grades (Chipuer \& Pretty, 1999; Conchas, 2001). As such, we predict that neighborhood belonging will be linked to adolescents' psychological well-being, as manifested by lower levels of anxiety and depression.

\section{The Current Investigation}

The present study explores Latino adolescents' sense of belonging in two important developmental contexts: schools and neighborhoods. Specifically, we test the model depicted in Figure 1. On the left side of the model, we examine how three

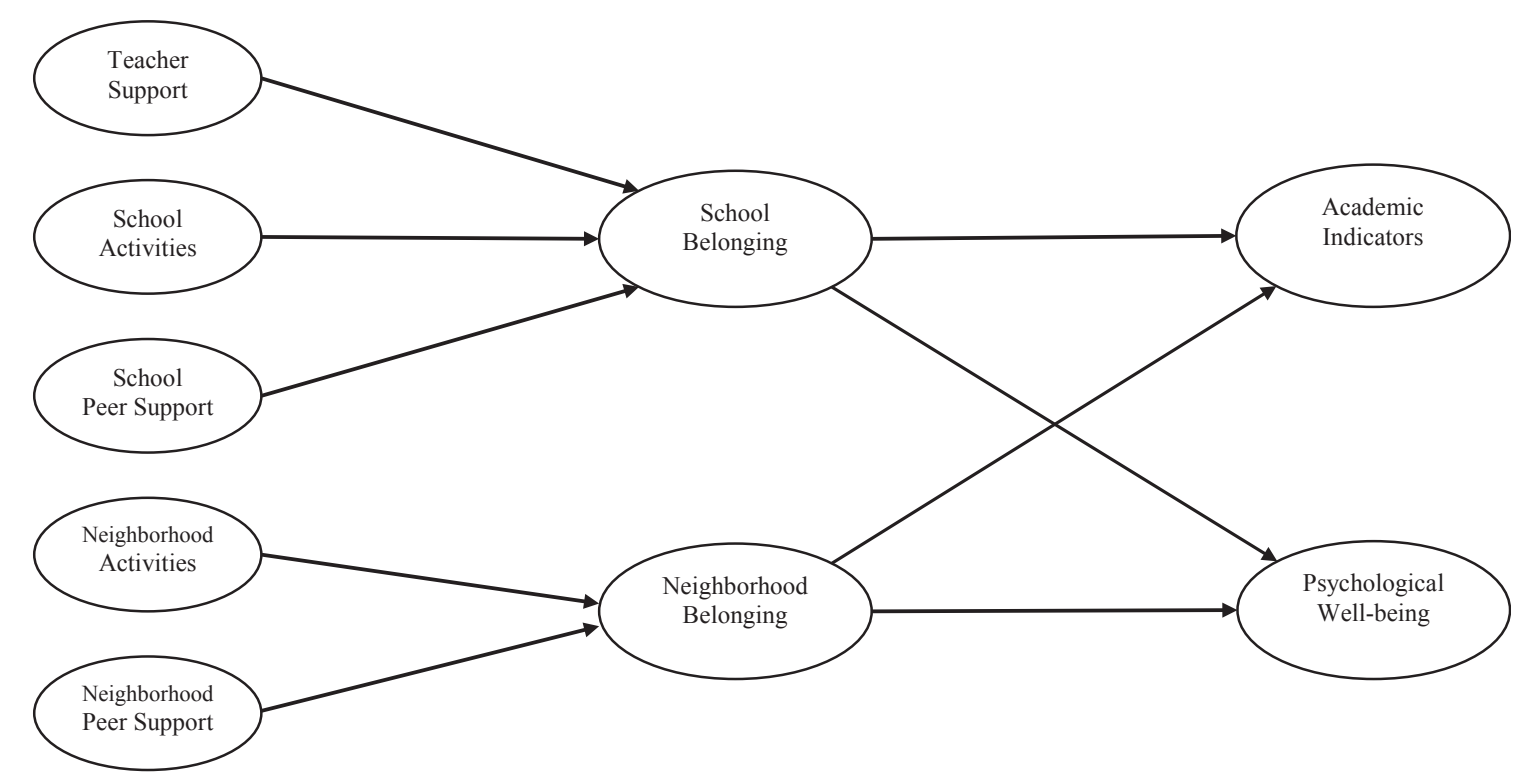

Figure 1. Hypothesized model showing the relations of school factors to school belonging, neighborhood factors to neighborhood belonging, and school and neighborhood belonging to academic outcomes and psychological well-being. Paths accounting for the covariance of error terms between control variables (school attended and sex) and all other variables in the model were omitted from the figure. 
factors (teacher support, school-based activities, and school peer support) contribute to adolescents' sense of school belonging and how two factors (neighborhood-based activities and neighborhood peer support) influence sense of neighborhood belonging. The next part of the model tests the relationship between adolescents' sense of school and neighborhood belonging and five academic outcomes-academic aspirations and expectations, self-reported grades, educational values, and school effort - and two indicators of psychological well-beinganxiety and depression. Because gender differences in school belonging and academic outcomes have been reported (Sanchez et al., 2005), our statistical analyses include gender as a control variable.

\section{Method}

\section{Participants}

Primary data were collected for 202 Latino students enrolled in the ninth grade, with an average age of 14.5 years $(S D=0.69)$. The students attended three schools in low-income, urban neighborhoods in the northeastern United States. Sixty-one percent of the sample was female and $39 \%$ of the sample was male. The majority of adolescents, $61 \%$, self-identified as Dominican (members of their family of origin are immigrants from the Dominican Republic). Dominicans comprise $19.8 \%$ of the Latino population in the northeastern United States, with $45.3 \%$ of Dominican children under 18 years old living below the poverty line compared with $38.9 \%$ of Latino children overall and $9.0 \%$ of non-Latino White children (U.S. Census Bureau, 2007). Other ethnicities reported by the adolescents included Columbian, Mexican, and Puerto Rican. Most of the students were born in the United States $(76 \%)$, and $54 \%$ of the sample reported speaking "mostly Spanish/some English" at home, while 31\% said they used "mostly English/some Spanish" in their homes.

Two schools were public schools and the other school was a parochial school. Seventy-seven students at the parochial school participated in the study, and about $68 \%$ of all students at this school qualified for free or reduced lunch. One of the public schools drew students from the same census tracts as the parochial school. This public school was subdivided according to student career interests; 46 students from the health and human services division and 41 students from the math, science, and technology division participated in this study. Eighty-two percent of the total student population in the health and human services division and $77 \%$ of students in the math, science, and technology division were eligible for free or reduced lunch. Thirty-one percent of Latino individuals in this district lived below the poverty threshold compared with $12 \%$ of the entire U.S. population (U.S. Census Bureau, 2007). At the second public school, 45 students participated in the study, and $96 \%$ of the total student population was eligible for free or reduced lunch. Thirty-five percent of Latino individuals in this school district lived below the poverty threshold (U.S. Census Bureau, 2007). Overall, participating students resided in 28 different census tracts.

\section{Procedures}

Recruitment letters, describing the study in both English and Spanish, were sent home with students. Only those who returned signed parental consent forms were able to participate. Students completed a self-report questionnaire during the regular school day in groups supervised by graduate and undergraduate research assistants. All adolescents were given the option to take the questionnaire in Spanish; Spanish versions of the questionnaire had been translated and then back-translated by native Spanish speakers. Seven students in our sample opted to take the Spanish version of the questionnaire with assistance from a bilingual graduate student and bilingual school teachers as needed. Participating students received a $\$ 30$ gift certificate to a local movie theater or mall as a token of appreciation for their participation.

\section{Measures}

Teacher support. Eight items from the Classroom Environment Scale (CES; Moos \& Trickett, 1987) were used to assess support from teachers. The teacher support subscale of the CES was conceptualized as a relationship dimension and has been widely used to assess the extent to which teachers take a personal interest in their students (Fraser \& Fisher, 1983; Moos \& Moos, 1978). Researchers who have used parts of the CES or the entire scale itself have obtained adequate reliability and validity (Fraser \& Fisher, 1983; Moos \& Moos, 1978; Nelson \& DeBacker, 2008). Response options ranged from 1 (none of them) to 3 (all of them) on items such as, "How many of your teachers treat you fairly?" and "How many of your teachers help you when you are sad or upset?" The mean of these items was calculated to create a final score, with higher scores reflecting greater teacher support. Cronbach's alpha was .73 for our sample.

Involvement in school-based activities. A measure to assess involvement in school versus neighborhood activities was specifically designed for this study. Involvement in schoolbased activities was measured by asking students to report how many times per week they engaged in a variety of activities: None, 1x/week, 2x/week, 3x/week, $4+x /$ week. There were six possible extracurricular activities: organized sports activities, playing sports with friends or alone, music or art activities and lessons, school clubs or organizations (e.g., drama, debate team, student government), volunteer work, and religious groups or activities. Students were then asked whether the activity was school related or not to differentiate between school-based and neighborhood-based activities. A scale was constructed by summing the total frequency of school-related activities that a student participated in, resulting in a range from 0 to 24 .

School peer support. Peer support was measured using the peer portion of the Inventory of Parent and Peer Attachment (IPPA-R; Gullone \& Robinson, 2005). The 25-item inventory includes three subscales of trust, communication, and 
alienation. Questions were administered to assess respondents' feelings about friends whom they see at school. We used the 9item trust subscale because these items best assessed supportive aspects of relationships with peers. Gullone and Robinson (2005) reported a Cronbach's alpha of .86 for this trust subscale. The IPPA from which the IPPA-R was adapted has been validated for use with adolescents (Armsden \& Greenberg, 1987). Response options ranged from 1 (never true) to 5 (always true) on items such as, "My school friends accept me as I am" and "I can count on my school friends to listen when something is bothering me." Scores were averaged with higher final scores indicting more positive peer support. For our sample, Cronbach's alpha was .89 for school peer support.

Involvement in neighborhood-based activities. Like school-based activities, neighborhood-based activities were measured by asking students to report how many times per week they engaged in a variety of activities in their neighborhoods: None, 1x/week, 2x/week, 3x/week, $4+x /$ week. As above, students differentiated between activities that were school based versus neighborhood based. There were six possible extracurricular activities: organized sports activities, playing sports with friends or alone, music or art activities and lessons, nonschool clubs or organizations (e.g., YMCA, 4-H), volunteer work, and religious groups or activities. A scale was constructed by summing the total frequency of neighborhood activities that each student participated in, resulting in a range from 0 to 24 .

Neighborhood peer support. The school peer support items were modified to assess adolescents' feelings of trust in and support from their neighborhood friends. Students responded to nine similar items that substituted "neighborhood friends" for "school friends," such as, "My neighborhood friends accept me as I am" and "I can count on my neighborhood friends to listen when something is bothering me." In answering these questions, students were asked whether they had neighborhood friends whom they did not see at school. We utilized a skip pattern, requiring students to answer these questions if they reported that they had friends whom they saw only in their neighborhoods. Consequently, $71 \%$ of students $(n=143)$ completed this section. Twenty-nine percent of students reported no neighborhood peer support, and these students did not differ from students who reported having neighborhood peer support with respect to sex, ethnicity, or any other study variables. Students responded to questions on a 5-point Likert scale. A mean of the items was calculated for a final score, with higher scores reflecting greater neighborhood peer support. Cronbach's alpha for this measure was .90 .

School belonging. Ten questions assessed adolescents' sense of school belonging. Five questions were adapted by Goodenow (1993) from Bollen and Hoyle (1990) and have been used with middle and high school students. These questions have been linked to socioemotional well-being, school effort, and academic achievement in ethnically diverse samples (Goodenow, 1993; McNeely \& Falci, 2004; Ozer, 2005; Resnick et al., 1997). Students indicated how strongly they agreed with statements like, "I feel close to people at this school" and "I feel like a real part of my school." Four additional questions were taken from Anderman's (2003) study on school belonging. These items were, "I wish I went to a different school," "I am proud of my school," "I can really be myself in this school," and "Sometimes I feel as if I don't belong at this school." The first and last questions were reverse-coded. Anderman (2003) reported an internal reliability of .80 for these items and an additional question, "I feel like a real part of this school" (included above), from Bollen and Hoyle (1990). One final item was adopted from Tyler and Degoey's (1995) work assessing whether students feel respected by adults at their school. This final item was, "I feel like a valued member of my school." Response options for all of these items ranged from 1 (strongly disagree) to 5 (strongly agree), and an average of all items was calculated for a final score, with higher scores indicating greater school belonging. Cronbach's alpha was .85 for our sample.

Neighborhood belonging. On a practical level, we wished to provide symmetry in our measures of adolescents' sense of belonging. Thus, for the purposes of our study, we adapted the school belonging measure to provide a similar measure of neighborhood belonging. For example, "I feel like a valued member of my school" was changed to "I feel like a valued member of my neighborhood," and "I feel like a real part of my school" became "I feel like a real part of my neighborhood." Equivalent changes were made for each of the 10 items on the school belonging measure. Similarly, response options ranged from 1 (strongly disagree) to 5 (strongly agree), the final score was an average of all items, and Cronbach's alpha for our sample was .87 .

Academic indicators. Academic aspirations. Students were asked one question to assess future academic aspirations: "How far would you like to go in school?" Response options included 1 (Finish some high school), 2 (Graduate from high school), 3 (Graduate from a 2-year college), 4 (Graduate from a 4-year college), and 5 (Graduate from law, medical, or graduate school). This measure is widely used and has been validated for use with Latino adolescents (Kao \& Tienda, 1998).

Academic expectations. Students were asked the following question to measure how much schooling they actually expected to complete: "How far do you actually think you will go in school?" Response options included 1 (Finish some high school), 2 (Graduate from high school), 3 (Graduate from a 2-year college), 4 (Graduate from a 4-year college), and 5 (Graduate from law, medical, or graduate school). Numerous studies have utilized this measure, and it has been validated for use with diverse student populations (Cheng \& Starks, 2002).

Grades. Grades were self-reported on a 7-point scale. Response options ranged from 1 (mostly D's) to 7 (mostly A's). Grades were converted to a traditional 4-point scale for analysis using the following formula (7: mostly A's $=4.0$; 6: A's and B's $=3.5 ; 5$ : mostly B's $=3.0$ and so on). Researchers have found that self-reported grades can correlate quite highly $(r=.76)$ with students' actual grades (Dornbusch, Ritter, Leiderman, Roberts, \& Fraleigh, 1987), supporting the validity of utilizing self-reported grades. 
Educational values. Measured by students' indication of the importance of education to them, educational values were assessed using a five-item scale developed by Fuligni, Witkow, and Garcia (2005) and included items such as, "It is important for me to do well in school," "It is important to go to college," and "It is important to be one of the best students in class." Response options ranged from 1 (not at all important) to 5 (extremely important). The average was calculated as the final score, with higher scores reflecting more belief in the value of education. These authors reported an internal consistency of .84 for Latino adolescents in their sample. Cronbach's alpha for our sample was .84 .

School effort. Students reported on the amount of effort they expend on schoolwork. This four-item scale was adapted from the study by Steinberg et al. (1992) and included the following questions: "How often do you really pay attention in class?" "How often do you hand in your homework on time?" "How often do you complete all assigned reading and homework before quizzes and tests?" and "How often do you study before a quiz or test?" Response options ranged from 1 (never) to 5 (almost always). An average final score was calculated, and Cronbach's alpha was .75 for our sample.

Psychological well-being indicators. Anxiety. Anxiety was assessed with the "What I Think and Feel Scale" (Reynolds \& Paget, 1981), the revised version of the Children's Manifest Anxiety Scale (Reynolds \& Richmond, 1978). This 27item measure consists of three subscales examining physiological anxiety, worry/oversensitivity, and concentration anxiety. Students were asked to indicate the frequency with which they felt anxious on a Likert scale with response options ranging from 1 (never) to 5 (most of the time). Example questions included: "How often do you wake up scared?" and "How often do you worry a lot of the time?" Scores for general anxiety were calculated by summing the mean scores from the three subscales, with higher scores representing greater levels of anxiety. For this sample, Cronbach's alpha was .94.

Depression. The Child Depression Inventory (CDI; Kovacs, 1985), a widely used instrument for measuring feelings of depression, was used to assess the depressive symptomatology of adolescents in our study. The CDI assesses symptoms of sadness, loneliness, and self-loathing and has demonstrated strong test-retest reliability and good validity (Finch, Saylor, Edwards, \& McIntosh, 1987; Hodges, Saunders, \& Kashani, 1990). This 26-item measure presents adolescents with groups of three statements, and they are asked to pick the statement that most closely describes how they have felt for the past 2 weeks. Each item is scored from 0 to 2, with reverse scoring as needed and a total score ranging from 0 to 52 . Higher scores indicate greater severity in depressive affect. The following cluster of three statements is an example item: "I am sad once in a while," "I am sad many times," and "I am sad all the time." Cronbach's alpha for our sample was .86 .

\section{Analytic Method}

The data were analyzed in two stages. First, multivariate analysis of variance (MANOVA) was conducted to compare students at each of the three schools in their perception of sup- port, extracurricular involvement, and feelings of belonging. Additionally, males and females were compared in their report of all study variables. In the second stage, structural equation modeling (SEM) analysis was conducted to examine factors associated with school and neighborhood belonging and the relationship between adolescents' sense of school and neighborhood belonging and several academic and psychological outcomes.

\section{Results}

Correlations between all of the variables used in this study are reported in Table 1. Interestingly, school belonging and neighborhood belonging were significantly and positively correlated $(r=.32, p<.001)$. Means, standard deviations, and ranges for all study variables as well as results for the MANOVA examining whether there were differences in key variables among students at the three schools are presented in Table 2. Differences between schools were observed in reported teacher support, $F(2,200)=8.22, p=.000$; school activities, $F(2,217)=5.23, p=.006$; school peer support, $F(2,200)=5.45$, $p=.005$; neighborhood peer support, $F(2,200)=11.43, p=$ .000 ; school belonging, $F(2,200)=4.57, p=.012$; and anxiety, $F(2,217)=4.67, p=.010$. Post hoc analyses using Tukey tests revealed differences between the parochial school and both public schools. There were greater levels of school peer support at the parochial school compared to public school 1 and greater levels of neighborhood peer support at the parochial school compared with both public schools. In contrast, levels of teacher support and school activity involvement were lower at the parochial school compared with both public schools. Students at public school 2 reported greater levels of school belonging than students at the parochial school. Finally, students at public school 1 reported lower levels of anxiety than students at both public school 2 and the parochial school. The school attended by adolescents was therefore included in the final model tested.

To examine the factors associated with school and neighborhood belonging and the relations between adolescents' sense of belonging in each context and their academic and psychological outcomes, we tested the model shown in Figure 1 using maximum likelihood estimates within a structural equation model framework. The model tested two pathways. The first path tested the relations between school support and activity variables and outcomes of academic functioning and psychological well-being via school belonging. Specifically, the first path tested the relations between teacher support, school activities, and school peer support and outcomes of academic and psychological functioning via school belonging. The second path tested the relations between neighborhood activities and neighborhood peer support and outcomes of academic and psychological functioning through neighborhood belonging. The model specified five academic outcomes - academic aspirations, academic expectations, self-reported grades, educational values, and school effort - in addition to two psychological outcomesanxiety and depression.

To avoid issues of biased measurement error typical of path analysis, we employed a latent variable model through partial disaggregation (Bagozzi \& Heatherton, 1994; Coffman \& 
Table 1. Correlations Among All Study Variables

\begin{tabular}{|c|c|c|c|c|c|c|c|c|c|c|c|c|c|}
\hline & \multicolumn{7}{|c|}{ School and neighborhood variables } & \multicolumn{6}{|c|}{ Academic and psychological outcomes } \\
\hline $\begin{array}{l}\text { 1. Teacher } \\
\text { support }\end{array}$ & - & & & & & & & & & & & & \\
\hline $\begin{array}{l}\text { 2. School } \\
\text { activities }\end{array}$ & $.15^{*}$ & - & & & & & & & & & & & \\
\hline $\begin{array}{l}\text { 3. School peer } \\
\text { support }\end{array}$ & .07 & -.04 & - & & & & & & & & & & \\
\hline $\begin{array}{l}\text { 5. Neighborhood } \\
\text { peer support }\end{array}$ & -.01 & -.05 & $.23^{* *}$ & $.27 * *$ & - & & & & & & & & \\
\hline $\begin{array}{l}\text { 6. School } \\
\text { belonging }\end{array}$ & $.48^{* * *}$ & .11 & $.37 * * *$ & .04 & .01 & - & & & & & & & \\
\hline $\begin{array}{l}\text { 7. Neighborhood } \\
\text { belonging }\end{array}$ & $.14^{*}$ & .05 & $.19 * *$ & $.20 * *$ & $.29 * * *$ & $.32 * * *$ & - & & & & & & \\
\hline $\begin{array}{l}\text { 10. Self-reported } \\
\text { grades }\end{array}$ & $.32 * * *$ & .04 & .12 & -.07 & -.02 & $.19^{* *}$ & -.04 & $.35 * * *$ & $.41 * * *$ & - & & & \\
\hline $\begin{array}{l}\text { 11. Educational } \\
\text { values }\end{array}$ & $.33 * * *$ & .12 & $.22 * *$ & .06 & -.07 & $.31 * * *$ & .04 & $.43 * * *$ & $.43^{* * *}$ & $.28 * * *$ & - & & \\
\hline 12. School effort & $.30 * * *$ & .11 & $.26 * * *$ & .06 & .06 & $.30 * * *$ & $.16^{*}$ & $.34 * * *$ & $.40 * * *$ & $.50 * *$ & $.52 * * *$ & - & \\
\hline 13. Anxiety & $-.22 * *$ & -.13 & .04 & -.09 & .03 & $-.23 * *$ & -.12 & -.03 & -.07 & -.06 & $-.15^{*}$ & -.11 & - \\
\hline 14. Depression & $-.27 * * *$ & -.11 & $-.27 * * *$ & -.13 & -.06 & $-.39 * *$ & $-.32 * * *$ & $-.22 * * *$ & $-.23 * * *$ & $-.21^{* *}$ & $-.29 * * *$ & $-.35^{* * *}$ & $.55^{* * *}$ \\
\hline
\end{tabular}

${ }^{*} p<.05 .{ }^{* *} p<.01 . * * * p<.001$.

Table 2. Variable Means and Standard Deviations by School

\begin{tabular}{|c|c|c|c|c|c|c|c|c|c|}
\hline Study variables & \multicolumn{3}{|c|}{ Full sample } & \multicolumn{2}{|c|}{ Public school 1} & \multicolumn{2}{|c|}{ Public school 2} & \multicolumn{2}{|c|}{ Parochial school } \\
\hline Teacher support & 1.84 & 0.59 & $0.00-3.00$ & 2.04 & 0.53 & $1.89^{\mathrm{b} 2}$ & 0.59 & $1.62^{\mathrm{c}}$ & 0.61 \\
\hline School peer support & 3.86 & 0.86 & $1.00-5.00$ & 3.59 & 0.92 & 3.79 & 0.89 & $4.06^{\mathrm{c} 2}$ & 0.75 \\
\hline Neighborhood activities & 3.79 & 4.16 & $0.00-24.00$ & 3.13 & 3.67 & 3.94 & 4.39 & 4.50 & 4.66 \\
\hline Neighborhood peer support & 2.70 & 1.54 & $1.00-5.00$ & 2.16 & 1.32 & $2.63^{\mathrm{b} 1}$ & 1.57 & $3.18^{\mathrm{c} 2}$ & 1.51 \\
\hline Academic aspirations & 4.57 & 0.78 & $1.00-5.00$ & 4.29 & 1.01 & 4.58 & 0.75 & 4.65 & 0.72 \\
\hline Academic expectations & 4.20 & 1.00 & $1.00-5.00$ & 4.06 & 0.95 & 4.13 & 1.11 & 4.31 & 0.88 \\
\hline Self-reported grades & 2.91 & 0.77 & $1.00-4.00$ & 2.91 & 0.76 & 2.84 & 0.89 & 2.94 & 0.64 \\
\hline Educational values & 4.30 & 0.63 & $1.00-5.00$ & 4.35 & 0.66 & 4.34 & 0.59 & 4.28 & 0.64 \\
\hline School effort & 3.76 & 0.68 & $1.00-5.00$ & 3.75 & 0.75 & 3.73 & 0.71 & 3.81 & 0.61 \\
\hline Anxiety & 7.12 & 2.17 & $3.00-15.00$ & $6.30^{\mathrm{a} 1}$ & 2.42 & 7.27 & 2.16 & $7.46^{\mathrm{c} 1}$ & 2.02 \\
\hline
\end{tabular}

${ }^{\mathrm{a} 1}$ Significant difference between public school 1 and public school $2(p<.05)$. ${ }^{\mathrm{b} 1}$ Significant difference between public school 2 and parochial school $(p<.05) ;{ }^{\mathrm{b} 2}(p<.01) .{ }^{\mathrm{c}}$ Significant difference between public school 1 and parochial school $(p<.001) ;{ }^{\mathrm{c} 2}(p<.01) ;{ }^{\mathrm{c} 1}(p<.05)$.

MacCallum, 2005). In a partially disaggregated model, several items are summed or averaged, resulting in parcels, and these parcels are used as indicators for latent constructs (Coffman \& MacCallum, 2005). Given the unidimensionality of scales for teacher support, peer school support, neighborhood peer support, school belonging, and neighborhood belonging, parcels were constructed by randomly assigning scale items to parcels (Kishton \& Widaman, 1994). The advantages of using parcels and indicators of constructs compared with items, as in total disaggregation, include more precise parameter estimates and higher reliabilities of parcels compared with items (Coffman \& MacCallum, 2005). In keeping with Bagozzi and Heatherton 
(1994), two parcels were constructed for scales having more than five items, whereas three parcels were constructed for scales having more than nine items.

We allowed free estimation of the covariance of the structural residuals among support and activities variables corresponding to the same context (i.e., teacher support, school activities, and school peer support; neighborhood activities and neighborhood peer support) and school and neighborhood belonging as well as between the five academic and two psychological outcome variables. The model was estimated by LISREL (version 8.53; Joreskog \& Sorbom, 2002) using maximum likelihood (ML) methodology. Missing data on the study variables ranged from $0 \%$ to $9.4 \%$ and was well below the recommended limit for the amount of missing data that can be accommodated by maximum likelihood estimation $(15.0 \%)$. In addition, missing data were equally distributed throughout the questionnaire. Figure 2 depicts all of the statistically significant standardized path coefficients for the hypothesized model with insignificant paths denoted by dashed lines.
The final model was also tested for group differences by gender and school attended by allowing for all direct paths from these two variables to the other 14 variables. For purposes of clarity, gender and school are not included in Figures 1 and 2, although differences according to gender and school are accounted for in the model. Table 3 provides means and standard deviations for all study variables by gender in addition to significant differences in the structural relations observed by gender in the model depicted in Figure 2. Males reported higher school activity involvement and school belonging, whereas females reported higher school peer support, selfreported grades, and school effort.

The model tested and shown in Figure 2 was well supported by the data $(\mathrm{CFI}=.96$, RMSEA $=.057)$. As an index that takes model complexity into account, an RMSEA of .08 or less is considered a reasonable fit. The CFI estimates the relative fit of the target model in comparison with the baseline model where all variables in the model are uncorrelated (Bentler, 1990; Hu \& Bentler, 1995). The values of CFI range from 0 to 1 with values greater than .95 indicating a good model fit.

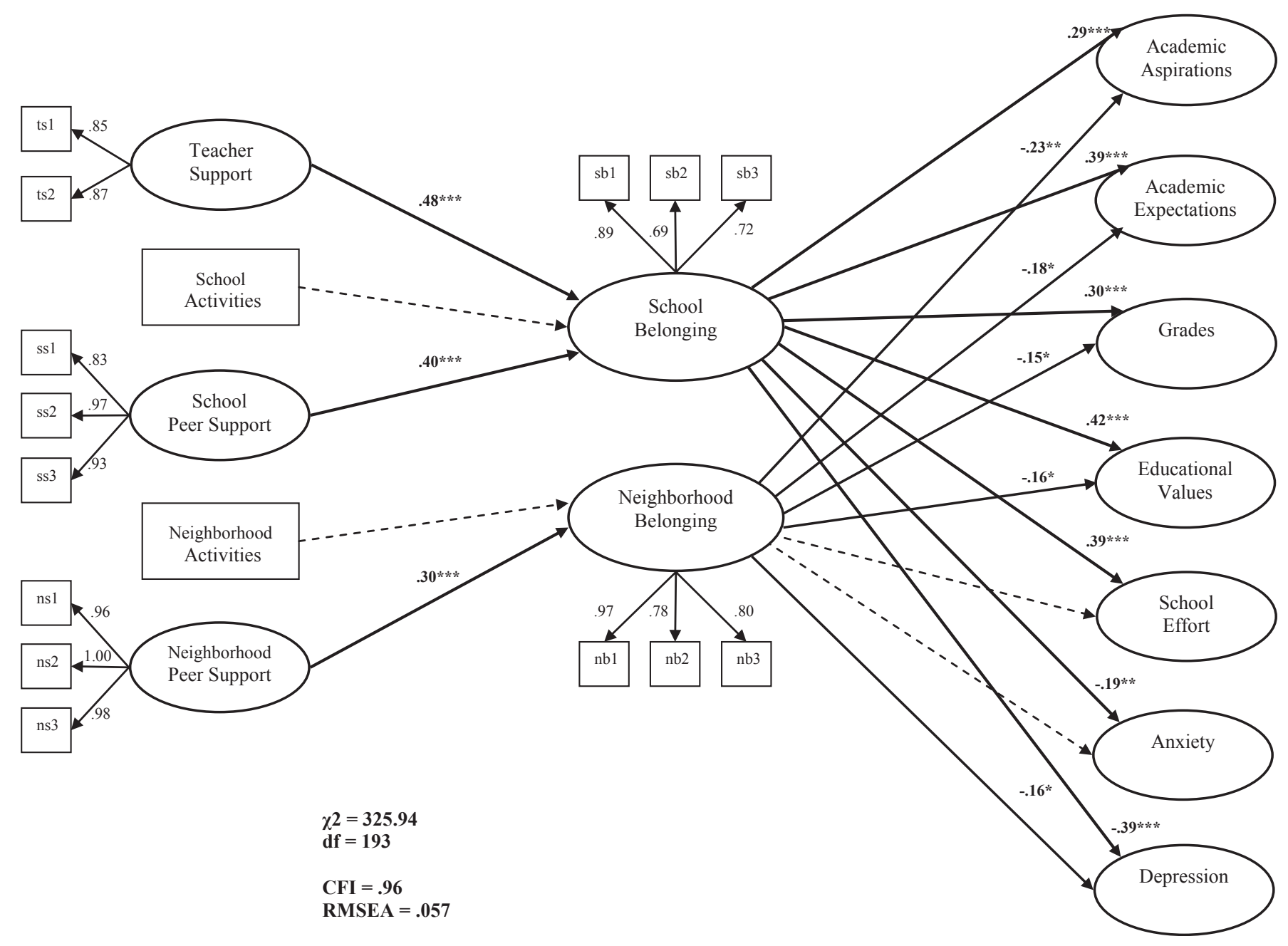

Figure 2. Structural model representing the relations of school factors to school belonging, neighborhood factors to neighborhood belonging, and school and neighborhood belonging to academic outcomes and psychological well-being. Only statistically significant standardized path coefficients $(p<.05)$ are shown. Solid lines represent significant relations, and dashed lines represent nonsignificant paths. ${ }^{*} p<.05 .{ }^{* *} p<.01 .{ }^{* * *} p<.001$. 
Table 3. Group Level Differences in Study Variables by Gender $(\mathrm{N}=202)$

\begin{tabular}{|c|c|c|c|c|c|c|c|c|}
\hline \multirow[b]{2}{*}{ Variable } & \multicolumn{3}{|c|}{ Full sample } & \multicolumn{2}{|c|}{ Males } & \multicolumn{2}{|c|}{ Females } & \multirow[b]{2}{*}{$\beta$} \\
\hline & $M$ & $S D$ & Range & $M$ & $S D$ & $M$ & $S D$ & \\
\hline Teacher support & 1.84 & 0.59 & $0.00-3.00$ & 1.89 & 0.63 & 1.80 & 0.59 & \\
\hline School activities & 1.88 & 2.82 & $0.00-24.00$ & 2.41 & 0.91 & 1.52 & 1.06 & $-.16 * *$ \\
\hline School peer support & 3.86 & 0.86 & $1.00-5.00$ & 3.62 & 0.90 & 4.01 & 0.82 & $.25 * * *$ \\
\hline Neighborhood activities & 3.79 & 4.16 & $0.00-24.00$ & 4.42 & 1.51 & 3.49 & 1.59 & \\
\hline Neighborhood peer support & 2.70 & 1.54 & $1.00-5.00$ & 2.73 & 0.96 & 2.68 & 0.95 & \\
\hline School belonging & 3.41 & 0.67 & $1.00-5.00$ & 3.54 & 0.63 & 3.32 & 0.69 & $-.24 * * *$ \\
\hline Neighborhood belonging & 3.15 & 0.71 & $1.00-5.00$ & 3.25 & 0.71 & 3.10 & 0.71 & \\
\hline Academic aspirations & 4.57 & 0.78 & $1.00-5.00$ & 4.47 & 0.79 & 4.63 & 0.82 & \\
\hline Academic expectations & 4.20 & 1.00 & $1.00-5.00$ & 4.06 & 0.97 & 4.29 & 1.01 & $.17 * * *$ \\
\hline Self-reported grades & 2.91 & 0.77 & $1.00-4.00$ & 2.74 & 0.78 & 3.03 & 0.74 & $.23 * * *$ \\
\hline Educational value & 4.30 & 0.63 & $1.00-5.00$ & 4.28 & 0.66 & 4.32 & 0.60 & \\
\hline School effort & 3.76 & 0.68 & $1.00-5.00$ & 3.61 & 0.73 & 3.86 & 0.64 & $.25 * * *$ \\
\hline Anxiety & 7.12 & 2.17 & $3.00-15.00$ & 6.10 & 2.09 & 7.75 & 2.02 & $.34 * * *$ \\
\hline Depression & 10.50 & 7.20 & $0.00-52.00$ & 9.30 & 6.92 & 11.23 & 7.34 & \\
\hline
\end{tabular}

Note. Male $=0$, female $=1$

$* * p<.01 . * * * p<.001$.

In keeping with our hypotheses, the model indicated that increased teacher support $(\beta=.48, p<.001)$ and school peer support $(\beta=.40, p<.001)$ were related to a greater sense of school belonging. As predicted, neighborhood peer support was significantly and positively linked to adolescents' sense of neighborhood belonging $(\beta=.30, p<.001)$. Further, our model indicated that school belonging was strongly associated with both academic outcomes and psychological well-being. School belonging was related to greater academic aspirations $(\beta=.29$, $p<.001)$, academic expectations $(\beta=.39, \quad p<.001)$, selfreported grades $(\beta=.30, p<.001)$, educational values $(\beta=.42$, $p<.001)$, and school effort $(\beta=.39, p<.001)$. School belonging was also associated with lower levels of anxiety $(\beta=-.19$, $p<.01)$ and depression $(\beta=-.39, p<.001)$. Similarly, neighborhood belonging was related to lower levels of depression $(\beta=-.16, p<.05)$. Contrary to our hypothesis, a greater sense of neighborhood belonging was significantly linked to lower academic aspirations $(\beta=-.23, p<.01)$, academic expectations $(\beta=-.18, p<.05)$, grades $(\beta=-.15, p<.05)$, and educational values $(\beta=-.16, p<.05)$.

\section{Discussion}

On the basis of prior findings in the literature, we expected several factors to contribute to school belonging and, by extension, neighborhood belonging among low-income, Latino adolescents. Surprisingly, we did not find a positive association between involvement in school-based or neighborhood-based activities and Latino adolescents' sense of belonging in either context. Although researchers have shown that engagement in extracurricular activities can have many positive effects on developmental outcomes (Dotterer, McHale, \& Crouter, 2007), research findings do not universally tout the benefits of extracurricular involvement on its own (Feldman \& Matjasko, 2005; Mahoney, 2000; Miller, Melnick, Barnes, Sabo, \& Farrell, 2007). For example, in one sample of Latino adolescent boys, involvement in extracurricular activities was associated with more problem behaviors in school (Prelow \& Loukas, 2003). In accord with our results, Faircloth and Hamm (2005) found that teacher and peer support were salient predictors of school belonging for Latino adolescents, whereas activity involvement was not. To understand how activities influence adolescents' feelings about their schools and neighborhoods, future work must gather more detailed, in-depth information about the nature of neighborhood activities. For example, is the activity well supervised by caring adults? Does the activity occur in a safe location? Does the adolescent voluntarily participate or feel pressured to participate by a parent? For the purposes of the present study, we were unable to collect such detailed information about adolescents' specific activities.

As hypothesized, teacher support and school peer support were significantly associated with school belonging. These results are in keeping with prior work in this area (Brown \& Evans, 2002; Faircloth \& Hamm, 2005). Additionally, as predicted, neighborhood peer support influenced students' sense of neighborhood belonging. Hence, positive and supportive relationships with teachers and peers emerged as an integral component of adolescents' sense of belonging in both school and neighborhood contexts. These findings emphasize the importance of relationships to adolescents' overall sense of belonging in different contexts. However, the context from which peer support is received may differentially impact adolescent outcomes. In this study, peer support in the school context contributed to school belonging, which was unequivocally related to positive outcomes. In contrast, neighborhood peer support was related to neighborhood belonging, thereby supporting greater psychological well-being; yet, neighborhood belonging was not associated with positive academic values, indicating that support from peers in the neighborhood may have an indirect, negative influence on academic outcomes.

In support of previous research, school belonging was related to multiple indicators of healthy adjustment, including academic attitudes and behavior (Anderman, 2003; Roeser et al., 1996; Steinberg et al., 1992) as well as socioemotional well-being (Chipuer, 2001; Ozer, 2005; Shochet et al., 2006). Specifically, school belonging was associated with higher 
academic aspirations, academic expectations, self-reported grades, educational values, and school effort. Additionally, school belonging was related to lower levels of both anxiety and depression. As was the case with school belonging, Latino adolescents with a greater sense of neighborhood belonging reported fewer symptoms of depression. It may be that these adolescents felt safer, more comfortable, and more connected to other people in their neighborhoods, ultimately resulting in better psychological functioning. However, neighborhood belonging was associated with lower academic aspirations, expectations, self-reported grades, and educational values. The neighborhoods in this study represent vibrant Latino communities that may enhance a sense of belonging for many of the Latino adolescents living there. Nevertheless, the neighborhoods are also economically disadvantaged, with approximately one third of all families living below the poverty line (U.S. Census Bureau, 2007). Adopting a sense of belonging to a lowincome neighborhood may limit adolescents' belief in the possibility or expectation of future educational attainment because neighborhood role models are less likely to have completed high school. Further, adolescents living in low-income neighborhoods with chronic environmental stressors may experience feelings of constrained choice (Rieker \& Bird, 2005) that restrict opportunities to choose education as a priority.

As this study demonstrates, examining the multiple components of school and neighborhood belonging can provide insight about the importance of different contexts for adolescents' academic and psychological functioning. Some researchers advocate the promotion of school belonging as an important entry point for interventions aimed at improving academic and psychological outcomes for youth (Anderman, 2003; Ibanez et al., 2004; Sanchez et al., 2005). Our study confirms the underlying rationale for interventions that take a more integrated approach in promoting positive developmental trajectories for low-income youth with academic adjustment as one, but not the only, element of successful transition into adulthood. Deciphering ways to increase adolescents' teacher support may be a key factor in increasing not only the academic success but also the psychological wellbeing of poor Latino adolescents via their sense of positive school belonging.

Fostering a sense of neighborhood belonging might, however, be a double-edged sword. On the one hand, our findings demonstrate that neighborhood belonging serves as a protective factor for adolescents with respect to psychological well-being, but our data also show a trend toward undermining positive educational outcomes. Although schools can be viewed as an integral part of one's neighborhood for many youth, our results suggest that in this particular population, students may experience school and neighborhood settings as incongruent contexts with inconsistent norms. Policy efforts to promote positive developmental outcomes among adolescents may also want to consider the sometimes conflicting role of multiple contexts. Clearly, more research is needed to explore the differential effects of school versus neighborhood contexts on adolescent functioning. Our study, with its uniquely Latino, primarily Dominican sample, provides preliminary findings and encouragement for future research on belonging to incorporate non-Latino youth and Latinos of other ethnicities as well as schools and neighborhoods of different racial and socioeconomic composition. Further, studies that explore possible interactions between adolescents' sense of school and neighborhood belonging are also warranted.

It is important to note the limitations of our investigation. First, our survey was limited by combining adolescent friendships into two categorical groups. In our survey, adolescents answered questions about the friends whom they saw at school. We then explicitly asked students to indicate whether they had any neighborhood friends whom they did not see at school. Thus, we obtained a clear indication of those adolescents who had a group of neighborhood friends who were separate from the friends they saw at school. Unfortunately, we were not able to ascertain how many of their friends overlapped in both school and neighborhood settings.

Second, the cross-sectional design of this study does not allow us to speak conclusively about the directionality of relations found. Anderman (2003) proposed that higher GPA may reinforce a student's sense of school belonging because of public acknowledgments of achievement like honor rolls and student-of-the-month awards. Thus, the relation between academic achievement and school belonging may, in fact, be reciprocal. Similarly, adolescents who are functioning better and who are more prosocial may feel more connected to their schools (Ozer, 2005). Future longitudinal research would help determine the directionality of these and other relations. Third, this study did not include family process variables or externalizing behaviors as outcomes. More research is needed to determine associations between a sense of home, school, and neighborhood belonging with adolescents' externalizing behaviors. Fourth, our study relied exclusively on measures of adolescent self-report that might inflate some of the associations because of common method bias. Finally, our sample size did not allow us to compare model fit by gender (Kline, 2011) or to tailor our research questions to specific subethnic Latino groups. Future work with larger sample sizes should avoid the tendency to overgeneralize between genders or among one racial or ethnic group and should examine relations within different Latino ethnic subgroups.

As this study demonstrates, examining multiple components of adolescents' school and neighborhood settings increases the possibility of determining what specific points of intervention may be most successful in promoting academic success and psychological well-being. Our finding that social supports were significantly associated with both school and neighborhood belonging for this low-income sample of students implies that seeking ways to foster positive interpersonal relationships in schools and neighborhoods may be essential to fostering psychological well-being among Latino adolescents. Promoting academic success, on the other hand, may be more complicated. Further investigation of both school and neighborhood factors is necessary to inform policies and effectively target those factors that may aid in the creation of culturally appropriate interventions aimed at improving academic and psychosocial functioning among low-income Latino youth.

Keywords: Latino adolescents; education; academic achievement; school belonging; neighborhood belonging; psychological well-being; teacher support; peer support 


\section{References}

Anderman, L. H. (2003). Academic and social perceptions as predictors of change in middle school students' sense of school belonging. Journal of Experimental Education, 72, 5-22.

Armsden, G. C., \& Greenberg, M. T. (1987). The inventory of parent and peer attachment-Individual differences and their relationship to psychological well-being in adolescents. Journal of Youth and Adolescence, 16, 427-454.

Bagozzi, R. P., \& Heatherton, T. F. (1994). A general approach to representing multifaceted personality constructs: Application to state self-esteem. Structural Equation Modeling, 1, 35-67.

Baumeister, R. F., \& Leary, M. R. (1995). The need to belong-Desire for interpersonal attachments as a fundamental human-motivation. Psychological Bulletin, 3, 497-529.

Bentler, P. M. (1990). Comparative fix indexes in structural models. Psychological Bulletin, 107, 238-246.

Bollen, K. A., \& Hoyle, R. H. (1990). Perceived cohesion-A conceptual and empirical examination. Social Forces, 69(2), 479-504.

Bronfenbrenner, U. (1989). Ecological systems theory. Annals of Child Development, 6, 187-249.

Bronfenbrenner, U. (1994). Ecological models of human development. In International Encyclopedia of Education, (2nd Ed., Vol. 3, pp. 1643-1647. Oxford: Elsevier.

Brown, R., \& Evans, W. P. (2002). Extracurricular activity and ethnicity-Creating greater school connection among diverse student populations. Urban Education, 37, 41-58.

Cheng, S., \& Starks, B. (2002). Racial differences in the effects of significant others on students' educational expectations. Sociology of Education, 75, 306-327.

Chipuer, H. M. (2001). Dyadic attachments and community connectedness: Links with youths' loneliness experiences. Journal of Community Psychology, 29, 429-446.

Chipuer, H. M., \& Pretty, G. H. (1999). A review of the sense of community index: Current issues, factor structure, reliability, and further development. Journal of Community Psychology, 27, 643-658.

Coffman, D. L., \& MacCallum, R. C. (2005). Using parcels to convert path analysis models into latent variable models. Multivariate Behavioral Research, 40, 235-259.

Conchas, G. Q. (2001). Structuring failure and success: Understanding the variability in Latino school engagement. Harvard Educational Review, 71, 475-504.

Dahl, T., Ceballo, R., \& Huerta, M. (2010). In the eye of the beholder: Mothers' perceptions of poor neighborhoods as places to raise children. Journal of Community Psychology, 38(4), 419-434.

Dornbusch, S. M., Ritter, P. L., Leiderman, P. H., Roberts, D. F., \& Fraleigh, M. J. (1987). The relation of parenting style to adolescent school performance. Child Development, 58, 1244-1257.

Dotterer, A. M., McHale, S. M., \& Crouter, A. C. (2007). Implications of out-of-school activities for school engagement in African American adolescents. Journal of Youth and Adolescence, 36, 391401.

Eccles, J. S. (2004). Schools, academic motivation, and stage-environment fit. In R. M. Lerner \& L. Steinberg (Eds.), Handbook of adolescent psychology (pp. 125-153). Hoboken, NJ: Wiley.

Eisenberg, M. E., Neumark-Sztainer, D., \& Perry, C. L. (2003). Peer harassment, school connectedness, and academic achievement. Journal of School Health, 73, 311-316.

Faircloth, B. S., \& Hamm, J. V. (2005). Sense of belonging among high school students representing 4 ethnic groups. Journal of Youth and Adolescence, 34, 293-309.

Feldman, A. F., \& Matjasko, J. L. (2005). The role of school-based extracurricular activities in adolescent development: A comprehensive review and future directions. Review of Educational Research, 75, $159-210$.

Finch, A. J., Saylor, C. F., Edwards, G. L., \& McIntosh, J. A. (1987). Children's Depression Inventory: Reliability over repeated administrations. Journal of Clinical Child Psychology, 16, 339-341.

Fogel, S. J. (2004). Risks and opportunities for success: Perceptions of urban youths in a distressed community and lessons for adults. Families in Society, 85, 335-344.

Fraser, B., \& Fisher, D. L. (1983). Use of actual and preferred classroom environment scales in person-environment fit research. Journal of Educational Psychology, 75, 303-313.

Fredricks, J. A., Blumenfeld, P. C., \& Paris, A. H. (2004). School engagement: Potential of the concept, state of the evidence. Review of Educational Research, 74, 59-109.

Fredricks, J. A., \& Eccles, J. S. (2005). Developmental benefits of extracurricular involvement: Do peer characteristics mediate the link between activities and youth outcomes? Journal of Youth and Adolescence, 34, 507-520.

Fredricks, J. A., \& Eccles, J. S. (2006). Is extracurricular participation associated with beneficial outcomes? Concurrent and longitudinal relations. Developmental Psychology, 42, 698-713.

Fuligni, A. J., Witkow, M., \& Garcia, C. (2005). Ethnic identity and the academic adjustment of adolescents from Mexican, Chinese, and European backgrounds. Developmental Psychology, 41, 799-811.

Garcia-Reid, P., Reid, R. J., \& Peterson, N. A. (2005). School engagement among youth in an urban middle school context: Valuing the role of social support. Education and Urban Society, 37, $257-275$.

Gonzalez, R., \& Padilla, A. M. (1997). The academic resilience of Mexican American high school students. Hispanic Journal of Behavioral Sciences, 19, 301-317.

Goodenow, C. (1993). The psychological sense of school membership among adolescents: Scale development and educational correlates. Psychology in the Schools, 30, 79-90.

Gullone, E., \& Robinson, K. (2005). The Inventory of Parent and Peer Attachment-Revised (IPPA-R) for children: A psychometric investigation. Clinical Psychology and Psychotherapy, 12, 67-79.

Herman, K. C., Reinke, W. M., Parkin, J., Traylor, K. B., \& Agarwal, G. (2009). Childhood depression: Rethinking the role of the school Psychology in the Schools, 46, 433-446.

Hirsch, B. J., Deutsch, N. L., \& DuBois, D. L. (2011). After-school centers and youth development. New York, NY: Cambridge University Press.

Hodges, K., Saunders, W. B., \& Kashani, J. (1990). Internal consistency of DSM-III diagnoses using the symptom scales of the Child Assessment Schedule. Journal of the American Academy of Child and Adolescent Psychiatry, 29, 635-641.

Hu, L., \& Bentler, P. M. (1995). Evaluating model fit. In R. H. Hoyle (Ed.), Structural equation modeling: Concepts, issues, and applications. Thousand Oaks, CA: Sage.

Ibanez, G. E., Kuperminc, G. P., Jurkovic, G., \& Perilla, J. (2004). Cultural attributes and adaptations linked to achievement motivation among Latino adolescents. Journal of Youth and Adolescence, 33 , $559-568$.

Joreskog, K. G., \& Sorbom, D. (2002). LISREL 8.53 for Windows [Computer software]. Skokie, IL: Scientific Software International.

Kao, G., \& Tienda, M. (1998). Educational aspirations of minority youth. American Journal of Education, 106, 346-385.

Kishton, J. M., \& Widaman, K. F. (1994). Unidimensional versus domain representative parceling of questionnaire items-An empirical example. Educational and Psychological Measurement, 54, 757-765.

Kline, R. (2011). Principles and practice of structural equation modeling. New York, NY: Guilford. 
Kovacs, M. (1985). The Children's Depression Inventory (CDI). Psychopharmacology Bulletin, 21, 995-998.

LaRusso, M. D., Romer, D., \& Selman, R. L. (2008). Teachers as builders of respectful school climates: Implications for adolescent drug use norms and depressive symptoms in high school. Journal of Youth and Adolescence, 37, 386-398.

Leventhal, T., \& Brooks-Gunn, J. (2004). A randomized study of neighborhood effects on low-income children's educational outcomes. Developmental Psychology, 40, 488-507.

Mahoney, J. L. (2000). School extracurricular activity participation as a moderator in the development of antisocial patterns. Child Development, 71, 502-516.

Mahoney, J. L., \& Cairns, R. B. (1997). Do extracurricular activities protect against early school dropout? Developmental Psychology, 33, 241-253.

Mahoney, J. L., Lord, H., \& Carryl, E. (2005). An ecological analysis of after-school program participation and the development of academic performance and motivational attributes for disadvantaged children. Child Development, 76, 811-825.

McNeely, C., \& Falci, C. (2004). School connectedness and the transition into and out of health-risk behaviour among adolescents: A comparison of social belonging and teacher support. Journal of School Health, 74, 284-292.

Miller, K. E., Melnick, M. J., Barnes, G. M., Sabo, D. F., \& Farrell, M. P. (2007). Athletic involvement and adolescent delinquency. Journal of Youth \& Adolescence, 36, 711-723.

Moos, R. H., \& Moos, B. S. (1978). Classroom social climate and student absences and grades. Journal of Educational Psychology, 70, 263-269.

Moos, R. H., \& Trickett, E. (1987). Classroom Environment Scale manual: CES. Palo Alto, CA: Consulting Psychologists Press.

National Center for Education Statistics. (2007). Status and trends in the education of racial and ethnic minorities. Washington, DC: U.S. Department of Education, Office of Educational Research and Improvement.

Nelson, K. M., \& DeBacker, T. K. (2008). Achievement motivation in adolescents: The role of peer climate and best friends. The Journal of Experimental Education, 76, 170-189.

Ozer, E. J. (2005). The impact of violence on urban adolescents: Longitudinal effects of perceived school connection and family support. Journal of Adolescent Research, 20, 167-192.

Prelow, H. M., \& Loukas, A. (2003). The role of resource, protective, and risk factors on academic achievement-related outcomes of economically disadvantaged Latino youth. Journal of Community Psychology, 31, 513-529.

Quane, J. M., \& Rankin, B. H. (2006). Does it pay to participate? Neighborhood based organizations and the social development of urban adolescents. Children and Services Review, 28, 1229-1250.

Resnick, M. D., Bearman, P. S., Blum, R. W., Bauman, K. E., Harris, K. M., Jones, J., ... Udry, J. R. (1997). Protecting adolescents from
harm-Findings from the National Longitudinal Study on Adolescent Health. Journal of the American Medical Association, 278, 823-832.

Reynolds, C. R., \& Paget, K. D. (1981). Factor analysis of the revised Children's Manifest Anxiety Scale for Blacks, Whites, males, and females with a national normative sample. Journal of Consulting and Clinical Psychology, 49, 352-359.

Reynolds, C. R., \& Richmond, B. O. (1978). What I think and feel: A revised measure of children's manifest anxiety. Journal of Abnormal Child Psychology, 6, 271-280.

Rieker, P. P., \& Bird, C. E. (2005). Rethinking gender differences in health: Why we need to integrate social and biological perspectives. Journals of Gerontology, Series B: Psychological Sciences and Social Sciences, 60, 40-47.

Roeser, R., Midgley, C., \& Urdan, T. C. (1996). Perception of the school psychological environment and early adolescents' psychological and behavioral functioning in school: The mediating role of goals and belonging. Journal of Educational Psychology, 88, 408-422.

Roosa, M. W., Jones, S., Tein, J. Y., \& Cree, W. (2003). Prevention science and neighborhood influences on low-income children's development: Theoretical and methodological issues. American Journal of Community Psychology, 31, 55-72.

Sanchez, B., Colon, Y., \& Esparza, P. (2005). The role of sense of school belonging and gender in the academic adjustment of Latino adolescents. Journal of Youth and Adolescence, 34, 619-628.

Shanahan, M. J., \& Flaherty, B. P. (2001). Dynamic patterns of time use in adolescence. Child Development, 72, 385-401.

Shochet, I. M., Dadds, M. R., Ham, D., \& Montague, R. (2006). School connectedness is an underemphasized parameter in adolescent mental health: Results of a community prediction study. Journal of Clinical Child and Adolescent Psychology, 35, 170-179.

Steinberg, L., Dornbusch, S. M., \& Brown, B. B. (1992). Ethnic differences in adolescent achievement-An ecological difference. American Psychologist, 47, 723-729.

Tyler, T. R., \& Degoey, P. (1995). Collective restraint in social dilemmas-Procedural justice and social identification effects on support for authorities. Journal of Personality and Social Psychology, 69, 482497.

U.S. Bureau of the Census. (2007). 2005-2007 American Community Survey 3-year estimates: Hispanic or Latino origin by specific origin. Retrieved from http://factfinder.census.gov/servlet/ACSSAFFPeople? _submenuId $=$ people_10\&_sse $=$ on

U.S. Bureau of the Census. (2011). 2009-2011 American Community Survey 3-year estimates: Hispanic or Latino origin by specific origin. Retrieved from http://factfinder2.census.gov/faces/nav/jsf/pages/searchresults.xhtml?refresh $=\mathrm{t}$

Water, S., Cross, D., \& Shaw, T. (2010). Does the nature of schools matter? An exploration of selected school ecology factors on adolescent perceptions of school connectedness. British Journal of Educational Psychology, 80, 381-402. 